\title{
Teor e composição química do óleo essencial de Hyptis marrubioides Epling (Lamiaceae) em diferentes genótipos
}

\author{
BOTREL, P.P. ; PINTO, J.E.B.P. ${ }^{1 *}$; FIGUEIREDO, F.C. ${ }^{2}$; BERTOLUCCI, S.K.V. ${ }^{1}$; FERRI, P.H. ${ }^{3}$ \\ ${ }^{1}$ Universidade Federal de Lavras (UFLA) - Departamento de Agricultura, Laboratório de Cultura de Tecidos e \\ Plantas Medicinais, Caixa Postal 3037, 37.200-000-Lavras - MG. botrelpp@bol.com.br; *jeduardo@ufla.br; \\ suzan@ufla.br ${ }^{2}$ Universidade Federal de Lavras (UFLA) - Departamento de Ciência do Solo, Caixa Postal 3037, \\ 37.200-000-Lavras-MG. doutorfcf@yahoo.com.br ${ }^{3}$ Universidade Federal de Goiás (UFG) - Instituto de Química, \\ Caixa Postal 131, 74001-970-Goiânia-GO.pedro@quimica.ufg.br
}

\begin{abstract}
RESUMO: Hyptis marrubioides Epling (hortelã-do-campo) é espécie de uso medicinal conhecida pelas suas atividades contra infecções gastrointestinais, infecções de pele, dores e câimbras. Objetivou-se com este trabalho, avaliar o teor e composição química do óleo essencial de $H$. marrubioides em diferentes genótipos (roxo e branco) e partes da planta fresca (folhas, inflorescências e caule). Os genótipos estudados foram identificados através das inflorescências das plantas que apresentam coloração roxa e branca. O delineamento experimental foi inteiramente casualizado, contendo as três partes da planta de ambos os genótipos, perfazendo um fatorial $3 \times 2$, com quatro repetições. O óleo essencial foi extraído por hidrodestilação por duas horas e analisado por Cromatografia Gasosa acoplada a Espectrometria de Massas (CG-EM). O maior teor de óleo essencial foi observado na inflorescência do genótipo roxo. A composição do óleo essencial de $H$. marrubioides variou quantitativamente entre as partes das plantas analisadas e entre os genótipos. O composto $\alpha$-tujona apresentou a maior porcentagem de área do pico nas inflorescências de genótipo roxo. As porcentagens das plantas com genótipo roxo foram em média superiores às plantas com genótipo branco.
\end{abstract}

Palavras-chave: hortelã-do-campo, planta medicinal, cromatografia gasosa

\begin{abstract}
Essential oil content and chemical composition in Hyptis marrubioides Epl. of different genotypes. Hyptis marrubioides Epling ("hortelã-do-campo") is a medicinal species known for its activities against gastrointestinal and skin infections, pains and cramps. The aim of this work was to evaluate essential oil content and chemical composition in $H$. marrubioides of different genotypes (purple and white), as well as fresh plant parts (leaves, inflorescences and stem). The studied genotypes were identified based on the inflorescences, which are purple and white. The experimental design was completely randomized, including the three parts of both genotypes, in a 3X2 factorial arrangement, with four replicates. Essential oil was extracted through hydrodistillation for two hours and analyzed using Gas Chromatography attached to a Mass Spectrometry (GC-MS). The highest essential oil content was found for the inflorescence of purple genotype. Hyptis marrubioides essential oil composition quantitatively varied among the analyzed plant parts and between genotypes. The compound $\alpha$-thujone had the highest percentage of apex area in inflorescences of purple genotype. The percentages of purple genotype were on average higher than those of white one.
\end{abstract}

Key words: "hortelã-do-campo", medicinal plant, gas chromatography

\section{INTRODUÇÃO}

O gênero Hyptis apresenta uma grande diversidade morfológica, principalmente na região do Cerrado brasileiro, com cerca de 300 a 400 espécies (Harley, 1988). Apresentam um aroma característico e são usadas no tratamento de infecções gastrointestinais, câimbras, dores e no tratamento de infecções da pele (Corrêa, 1931). Também possuem efeito anestésico, antiespasmódico,

Recebido para publicação em 28/04/2008

Aceito para publicação em 12/09/2008

Rev. Bras. PI. Med., Botucatu, v.11, n.2, p.164-169, 2009. 
antinflamatório, além de abortivo em doses elevadas (Di Stasi et al., 1996).

Hyptis marrubioides é também conhecida como hortelã-do-campo e pertence a família Lamiaceae. As Lamiaceaes compreendem uma família pertencente à Ordem Tubiflorae (Lamiales), abrangendo cerca de 200 gêneros e, aproximadamente, 3.200 espécies, distribuídas em todo o mundo.

Estudos recentes têm mostrado atividades biológicas importantes relacionadas ao gênero Hyptis, tais como: como atividades antifúngica (De Oliveira et al., 2004), antibacteriana (Souza et al., 2003), antiulcerogênica (Barbosa \& Ramos, 1992), larvicida (Costa et al., 2005), e antidepressiva (Bueno et al., 2006), dentre outras.

Nas regiões tropicais e subtropicais, onde a diversidade vegetal é muito grande, o conhecimento do potencial dos recursos genéticos de plantas medicinais e aromáticas deve ser uma busca constante (Martins et al., 1997).

Fatores como variabilidade genética intraespecífica, condições ambientais, épocas de colheita, condições de cultivo, tipo de solo e parte da planta analisada, podem influenciar no teor e na composição química dos óleos essenciais (Hay \& Svoboda, 1993). Todos esses aspectos são de fundamental importância quando se realiza o desenvolvimento de trabalhos de melhoramento de uma espécie medicinal visando a aplicação fitoterapêutica, uma vez que a qualidade dos óleos essenciais está ligada a sua constituição química.

Os principais constituintes químicos encontrados por Sales et al. (2007) em H. marrubioides, ao estudar a variabilidade química presente no óleo essencial desta espécie em duas localidades da região do Cerrado brasileiro, foram cariofila-4(14),8(15)-dien$5 \beta$-ol, eudesma-4(15),7-dien-1 $\beta$-ol, óxido de cariofileno e $(\beta)$-cariofileno.

Na obtenção da matéria-prima, as técnicas de cultivo da espécie selecionada devem atender ao objetivo de aumentar a produção de biomassa por área, sem comprometer o valor terapêutico da planta (Castro et al., 2004). Neste aspecto, a escolha da parte da planta é de fundamental importância, visto que ela deve apresentar maior teor de óleo essencial para uma possível produção comercial e maior concentração do seu princípio ativo.

O objetivo desse trabalho foi verificar o teor e composição química do óleo essencial em inflorescências, folhas e caules em dois genótipos de Hyptis marrubioides.

\section{MATERIAL E MÉTODO}

Material vegetal e cultivo

O experimento foi conduzido no Laboratório de Cultura de Tecidos e Plantas Medicinais da
Universidade Federal de Lavras (UFLA), MG, situada nas coordenadas geográficas $21^{\circ} 14^{\prime}$ de Latitude Sul e $45^{\circ} 00^{\prime}$ de Longitude Oeste de Greenwich a uma altitude de $918 \mathrm{~m}$.

A exsicata desta espécie está depositada no herbário da UFLA, sob o código ESAL 13955 e foi coletada em Tiradentes, MG.

As mudas de $H$. marrubioides foram obtidas através de propagação in vitro, onde as plantas oriundas de ápices caulinares de brotações jovens de plantas do campo foram estabelecidas em meio de cultura MS (Murashige \& Skoog, 1962) e submetidas posteriormente a repicagens a cada 15 dias durante seis meses.

Após o cultivo das plantas in vitro, estas foram transplantadas no dia 16 de maio de 2007, para bandejas contendo substrato Plantimax ${ }^{\circledR}$, onde permaneceram por 30 dias sob irrigação em casa de vegetação aclimatizada. Após a aclimatização, foram selecionadas 30 mudas, onde cada uma foi plantada individualmente em vaso plástico contendo 10 litros de composto orgânico que foram irrigados três vezes por semana.

\section{Coleta e preparo das amostras}

Após aproximadamente 110 dias do transplantio, com o florescimento das plantas, foram selecionadas aleatoriamente 11 plantas com inflorescências roxas (genótipo roxo) e 11 plantas com inflorescências brancas (genótipo branco).

Neste período, realizou-se a coleta das folhas, inflorescências e caules próximo das 9 horas da manhã no dia 18 setembro de 2007. Foram coletadas amostras compostas de ambos genótipos, e destas, foram retiradas $60 \mathrm{~g}$ de cada parte da planta para a extração do óleo essencial do material fresco. As partes que não foram extraídas no momento da coleta foram guardadas no refrigerador até o momento da extração do óleo essencial.

O delineamento experimental foi inteiramente casualizado, contendo as três partes da planta (inflorescências, folhas e caules) dos dois genótipos (roxo e branco), perfazendo um fatorial $3 \times 2$, com quatro repetições cada totalizando 24 parcelas.

\section{essencial \\ Extração e composição química do óleo}

As partes da planta foram então submetidas a hidrodestilação em aparelho de Clevenger modificado (Wasicky, 1963) durante duas horas. O óleo essencial foi purificado por partição líquido-líquido com diclorometano. A fase orgânica foi reunida $e$ tratada com $5 \mathrm{~g}$ de sulfato de magnésio anidro durante 30 minutos. Após esse período a solução foi filtrada e o solvente evaporado em temperatura ambiente, sob capela de exaustão de gases. O teor dos óleos essenciais foi determinado pelas massas obtidas dos 
óleos, e expresso em porcentagem massa/massa ( 9 de óleo por $100 \mathrm{~g}$ de matéria fresca).

As análises de composição química dos óleos essenciais foram realizadas em um aparelho de Cromatografia Gasosa acoplada a um Espectrômetro quadrupolar de Massas (CG-EM), Shimadzu ${ }^{\circledR}$ QP5050A (Kyoto, Japão), nas seguintes condições operacionais: coluna capilar de sílica fundida, modelo CBP-5 (30 m de comprimento $\times 0,25$ $\mathrm{mm}$ de diâmetro interno $\times 0,25 \mu \mathrm{m}$ de espessura do filme em $5 \%$ de fenilmetilpolisiloxano) (Shimadzu ${ }^{\circledR}$, Japão), com fluxo de $1 \mathrm{~mL} \mathrm{~min}^{-1}$ de hélio como gás de arraste; aquecimento com temperatura programada $\left(60^{\circ} \mathrm{C} \mathrm{com}\right.$ um gradiente de $3^{\circ} \mathrm{C} \mathrm{min}^{-1}$ até $240^{\circ} \mathrm{C}$ e, em seguida, com um gradiente de $10^{\circ} \mathrm{C}$ $\mathrm{min}^{-1}$ até $270^{\circ} \mathrm{C}$, mantendo-se uma isoterma de $7 \mathrm{~min}$, com um tempo total de corrida de $70 \mathrm{~min}$ ). A energia de ionização do detector foi de 70 e $\mathrm{V}$, sendo o volume de injeção da amostra de 0,5 $\mu \mathrm{L}$ diluídas em diclorometano (grau ultra-resíduo, Baker, EUA) e uma razão de injeção de 1:20. As temperaturas do injetor e do detector foram mantidas em $220^{\circ} \mathrm{C}$ e $240^{\circ} \mathrm{C}$, respectivamente. $A$ análise foi conduzida no modo varredura, a uma velocidade de 1,0 varredura s ${ }^{-1}$, com um intervalo de massas de 40-400 m/z. A análise quantitativa foi obtida pela integração do cromatograma total de íons (TIC). A identificação dos constituintes foi realizada por comparação, automática e manual, dos espectros de massas com os das bibliotecas NIST/EPA/NHI (1998), por comparação dos espectros de massas e índices de retenção (IR) com os da literatura (Adams, 2001) e co-injeção com padrões autênticos. Os Índices de Retenção foram calculados através da co-injeção com uma mistura de hidrocarbonetos, C8-C32 (Sigma, EUA), e com aplicação da equação de Van Den Dool e Kratz (1963).

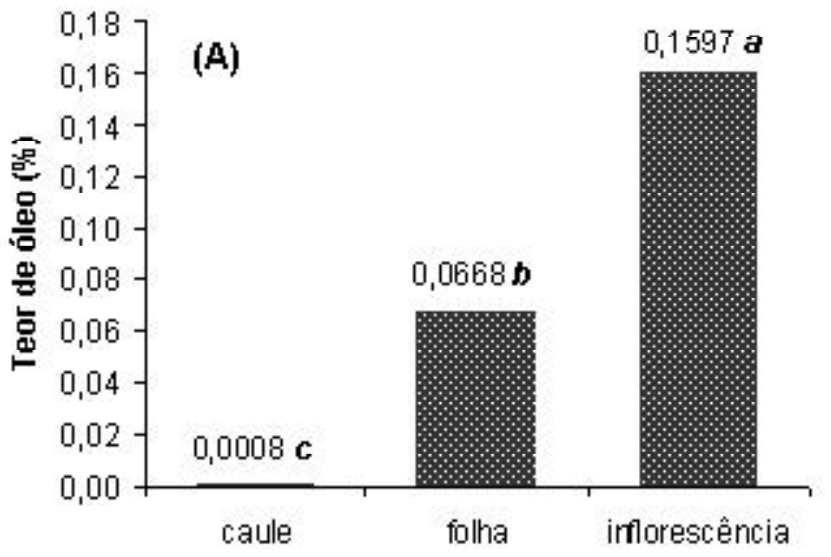

Parte da planta

\section{RESULTADOE DISCUSSÃO}

\section{Teor do óleo essencial}

Foram observadas características organolépticas distintas para os óleos obtidos dos diferentes genótipos. Para plantas com inflorescência roxa, o óleo essencial apresentou coloração amarelada, já para plantas com inflorescência branca, este apresentou coloração mais clara, quase incolor. Os óleos essenciais apresentaram pouca viscosidade e odor forte característico da planta fresca, sendo este mais acentuado nas plantas de genótipo roxo.

Na Figura 1, podem-se verificar os resultados do teor de óleo essencial para as variáveis analisadas. Observa-se que foram significativas as diferenças entre os teores de óleo obtidos nas diferentes partes da planta e nos genótipos.

Independente da parte da planta o genótipo roxo apresentou maior teor de óleo essencial, sendo as inflorescências a parte mais produtiva.

O teor de óleo essencial das inflorescências nas plantas de genótipo roxo $(0,1597 \%)$ foi significativamente diferente do teor obtido nas folhas $(0,0668 \%)$. No entanto, a quantidade de inflorescências disponíveis na planta é bem menor comparado à quantidade de folhas, além do fato de que esta espécie floresce apenas uma vez por ano, o que inviabilizaria uma extração de óleo comercial das inflorescências, mesmo apresentando o maior teor de óleo.

Observou-se também que para os dois genótipos estudados, as inflorescências de $H$. marrubioides produziram maior teor de óleo do que nas folhas e nos caules. Resultado semelhante foi também observado em plantas de Hyptis spicigera Lam., em que as folhas frescas produziram $0,13 \%$, enquanto, as inflorescências frescas, produziram

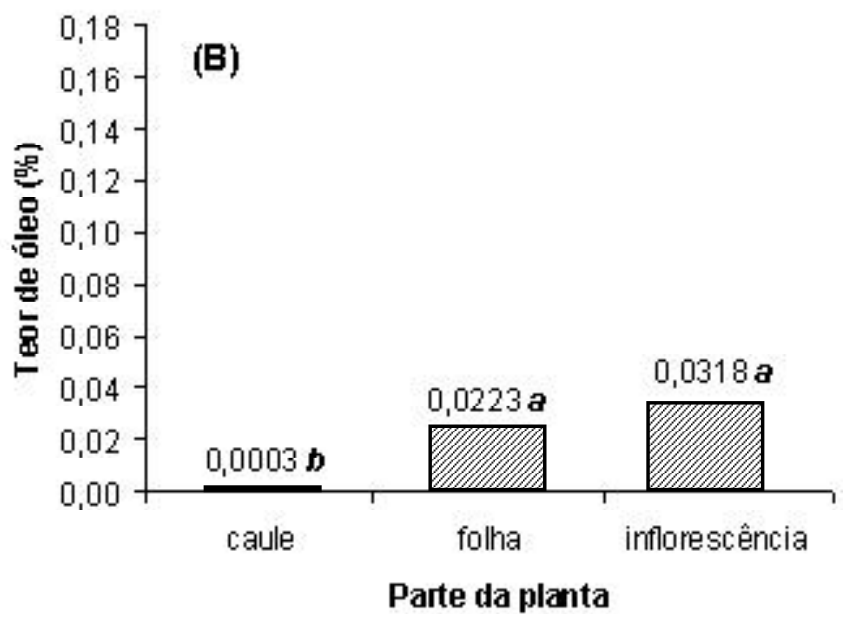

FIGURA 1. Valores médios do teor de óleo essencial, em porcentagem, extraído da massa fresca de três partes da planta (caule, folha e inflorescência) do genótipo roxo de Hyptis marrubioides (A) e do genótipo branco de Hyptis marrubioides (B). 
quase três vezes mais óleo (0,37\%) (Kini et al., 1993).

Silva et al. (2003), estudando o teor de óleo essencial nas folhas, caules e inflorescências frescas de $H$. suaveolens, observaram que as inflorescências também continham maior teor de óleo essencial $(0,068 \%)$ em relação aos caules $(0,007 \%)$ e folhas $(0,030 \%)$.

Nos dois genótipos estudados o caule foi a parte da planta que apresentou o menor teor de óleo essencial. Esse fato pode ser explicado pela presença de estruturas bastante lignificadas presentes no caule, o que diminuiria a necessidade de haver estruturas protetoras de óleo essencial. Além disso, o caule não é um tecido preferencial para ataque de herbívoros.

\section{Composição química do óleo essencial}

A composição química do caule não pôde ser analisada pelo fato da concentração do óleo essencial desta parte da planta ter sido insuficiente para realização das análises cromatográficas.

TABELA 1. Porcentagem de área dos picos cromatográficos correspondentes aos compostos identificados no óleo essencial das inflorescências e folhas de Hyptis marrubioides nos genótipos branco e roxo.

\begin{tabular}{|c|c|c|c|c|c|c|}
\hline \multirow{3}{*}{ IK } & \multirow{3}{*}{ Constituintes } & \multirow{3}{*}{ Classe } & \multicolumn{2}{|c|}{ Genótipo branco } & \multicolumn{2}{|c|}{ Genótipo roxo } \\
\hline & & & Flor & Folha & Flor & Folha \\
\hline & & & \multicolumn{4}{|c|}{$\%$ área } \\
\hline 1098 & linalool & MO & 0.9 & 1.0 & 1.1 & 1.0 \\
\hline 1104 & $\beta$-tujona & MO & 1.7 & 1.7 & 15.9 & 8.8 \\
\hline 1114 & $\alpha$-tujona & $\mathrm{MO}$ & 7.1 & 6.4 & 41.0 & 25.1 \\
\hline 1132 & iso-3-tujanol & MO & 0.8 & 2.4 & 0.7 & 2.0 \\
\hline 1138 & $\alpha$-pinocarveol & $\mathrm{MO}$ & 1.3 & 2.8 & 0.9 & 1.4 \\
\hline 1143 & $\beta$-verbenol & MO & 2.5 & 2.5 & 1.7 & 2.1 \\
\hline 1171 & ß-3-pinocanfona & MO & 2.4 & 1.8 & 5.8 & 4.2 \\
\hline 1175 & terpinen-4-ol & MO & 2.1 & 2.0 & 1.9 & 1.0 \\
\hline 1138 & $\alpha$-terpineol & MO & 2.6 & 2.1 & 1.6 & 1.9 \\
\hline 1296 & mirtenato de metila & MO & 0.9 & 1.0 & 0.1 & 0.1 \\
\hline 1375 & $\alpha$-copaeno & $\mathrm{SH}$ & 4.6 & 5.0 & 4.7 & 7.6 \\
\hline 1419 & $\beta$-cariofileno & $\mathrm{SH}$ & 12.8 & 12.6 & 6.5 & 11.8 \\
\hline 1453 & a-humuleno & $\mathrm{SH}$ & 0.8 & 1.2 & 0.4 & 0.9 \\
\hline 1480 & y-muuroleno & $\mathrm{SH}$ & 18.1 & 18.9 & 8.4 & 16.7 \\
\hline 1483 & y-himachaleno & $\mathrm{SH}$ & 0.0 & 0.0 & 3.7 & 6.5 \\
\hline 1514 & Y-cadineno & $\mathrm{SH}$ & 1.4 & 1.4 & 0.5 & 0.8 \\
\hline 1550 & epóxido de italiceno & SO & 2.8 & 1.6 & 0.1 & 0.1 \\
\hline 1557 & $\begin{array}{l}\text { epóxido de italiceno (isômero } \\
\text { desconhecido) }\end{array}$ & $\mathrm{SO}$ & 1.3 & 0.9 & 0.1 & 0.1 \\
\hline 1573 & dendrolasina & $\mathrm{SO}$ & 1.5 & 0.8 & 0.1 & 0.1 \\
\hline 1581 & óxido de cariofileno & SO & 8.1 & 3.9 & 0.9 & 1.2 \\
\hline 1631 & cariofila-4(14),8(15)-dien-5-a-ol & so & 2.3 & 1.1 & 0.1 & 0.1 \\
\hline 1635 & cariofila-4(14),8(15)-dien-5- $\beta$-ol & $\mathrm{SO}$ & 7.8 & 5.6 & 0.7 & 1.1 \\
\hline 1649 & $\beta$-eudesmol & SO & 3.3 & 3.7 & 0.1 & 0.1 \\
\hline 1652 & a-eudesmol & so & 1.1 & 2.2 & 0.1 & 0.1 \\
\hline 1669 & 14-hidróxi-(Z)-cariofileno & $\mathrm{SO}$ & 1.5 & 1.0 & 0.1 & 0.1 \\
\hline 1684 & germacra-4(15),5,10(14)-trien-1- $\alpha$-ol & $\mathrm{SO}$ & 8.0 & 10.4 & 2.2 & 4.2 \\
\hline \multicolumn{2}{|c|}{ Total dos monoterpenos (MO) } & & 22.3 & 23.7 & 70.7 & 47.6 \\
\hline \multicolumn{2}{|c|}{ Total dos sesquiterpenos hidrocarbonetos (SH) } & & 37.7 & 39.1 & 24.2 & 44.3 \\
\hline \multicolumn{2}{|c|}{ Total dos sesquiterpenos oxigenados (SO) } & & 37.7 & 31.2 & 4.5 & 7.2 \\
\hline \multicolumn{2}{|c|}{ Sesquiterpenos totais } & & 75.4 & 70.3 & 28.7 & 51.5 \\
\hline \multicolumn{2}{|c|}{ TOTAL } & & 97.7 & 94.0 & 99.4 & 99.1 \\
\hline
\end{tabular}

Rev. Bras. PI. Med., Botucatu, v.11, n.2, p.164-169, 2009. 
Os componentes majoritários do óleo essencial nos dois genótipos diferenciaram na porcentagem em relação à classe de monoterpenos e sesquiterpenos. Observa-se na Tabela 1, que no genótipo branco, tanto em folhas como em inflorescências, predominaram sesquiterpenos. No genótipo roxo, a folha mostrou um equilíbrio entre mono e sesquiterpenos. No entanto, nas inflorescências, a classe de monoterpenos apresentou uma porcentagem relativa de $70,7 \%$.

Estudando a composição química do óleo essencial das folhas e flores de dois acessos de Ocimum selloi Benth., Martins et al. (1997) encontraram como componente principal para o acesso A o estragol, o qual representou 94,95 e $92,54 \%$ do óleo das folhas e flores, respectivamente. Já o óleo obtido das folhas e flores do acesso B foi constituído de 65,49 e $66,18 \%$ de metil-eugenol, respectivamente. No óleo essencial de $H$. marrubioides, observou-se mudanças qualitativas apenas para o composto $y$-himachaleno, o qual não foi identificado nas inflorescências e folhas do genótipo branco. Para os demais compostos, foram observadas grandes diferenças quantitativas entre as partes da planta analisadas e os genótipos, com base nas porcentagens das áreas dos picos.

Os componentes $\alpha$-tujona e $\beta$-tujona apresentaram a maior porcentagem nas inflorescências de genótipo roxo, 41 e 15,9\%, respectivamente. A porcentagem de área dos picos desses compostos foi sempre maior no genótipo roxo tanto para folhas quanto para as inflorescências. As porcentagens nas inflorescências de genótipo roxo chegaram a ser até nove vezes maiores, comparadas ás inflorescências de genótipo branco.

Para os compostos $\mathrm{y}$-muuroleno, $\beta$ cariofileno, óxido de cariofileno, cariofila-4(14),8(15)dien-5- $\beta$-ol e germacra-4(15),5,10(14)-trien- 1 - $\alpha$-ol houve uma inversão, apresentando maiores porcentagens nas plantas de genótipo branco.

Silva et al. (2003) obtiveram um número diferente de picos para as folhas (45 picos), inflorescências (27 picos) e caules (44 picos) analisados no cromatograma do óleo essencial de $H$. suaveolens. Queiroz et al. (1990) sugerem que nesta espécie pode haver alocação de recursos para a floração e um decréscimo na produção de terpenos. Este fato não foi observado para $H$. marrubioides que apresentou o mesmo número de picos para as partes da planta analisadas (26 picos).

Sales et al. (2007), estudando o óleo essencial de Hyptis marrubioides de caules e folhas (frescos, secos e inteiros ou em pedaços) coletados em duas localidades do cerrado brasileiro, identificaram 26 compostos que representaram 96$99 \%$ dos constituintes voláteis. Sesquiterpenos oxigenados foram os principais grupos de constituintes na maioria das populações (52.9-93.2\%). No entanto, importantes diferenças foram observadas nos teores da maioria dos constituintes para caules e folhas. $E$ os materiais de plantas inteiras ou em pedaços resultaram em composições químicas similares.

Este trabalho permitiu concluir que a parte da planta de $H$. marrubioides que apresentou o maior teor de óleo essencial é a inflorescência. Com relação á composição química do óleo essencial, as porcentagens das plantas com genótipo roxo foram em média superiores às plantas com genótipo branco. Por ser um trabalho fitotécnico, sugere-se a realização de novos experimentos que revelem quais fatores estão influenciando estas diferenças, principalmente estudos genéticos e morfológicos.

\section{AGRADECIMENTO}

A CAPES, CNPq e FAPEMIG pelo fornecimento da bolsa e apoio financeiro.

\section{REFERÊNCIA}

ADAMS, R.P. Identification of essential oil components by gas chromatography/quadrupole mass spectroscopy. Illinois: Allured Publishing Corporation, 2001. 456p. BARBOSA, P.P.P.; RAMOS, C.P. Studies on the antiulcerogenic activity of the essential oil of Hyptis mutabilis Briq in rats. Phytotherapy Research, v.6, p.1145, 1992.

BUENO, A.X. et al. Effects of the aqueous extract from Hyptis pectinata leaves on rodent central nervous system. Revista Brasileira de Farmacognosia, v.16, p.317-23, 2006.

CASTRO, H.G. et al. Contribuição ao estudo das plantas medicinais: metabólitos secundários. Viçosa: UFV, 2004. $113 p$.

CORRÊA, M.P. Dicionário das plantas úteis do Brasil e das exóticas cultivadas. Rio de Janeiro: Ministério da Agricultura/ IBDF, 1931. 747p.

COSTA, J.G.M. et al. Estudo químico-biológico dos óleos essenciais de Hyptis martiusii, Lippia sidoides e Syzigium aromaticum frente às larvas do Aedes aegypti. Revista Brasileira de Farmacognosia, v.15, p.304-9, 2005.

DE OLIVEIRA, C.M.A. et al. Chemical composition and antifungal activity of the essential oil of Hyptis ovalifolia Benth. (Lamiaceae). Journal of the Brazilian Chemical Society, v.15, p.756-9, 2004.

DI STASI, L.C. et al. Plantas medicinais arte e ciência: Um guia de estudo interdisciplinar. São Paulo: UNESP, 1996. 230p.

HARLEY, R.M. Evolution and distribution of Eriope (Labiatae) and its relatives in Brasil. In: VANZOLINI, P.E.; HEYER, W.R. (Eds.). Proceedings patterns. Rio de Janeiro: Academia Brasileira de Ciências, 1988. p.7180.

HAY, R.K.M.; SVOBODA, K.P. Botany. In: HAY, R.K.M.; 
WATERMAN, P.G. Volatile oil crops: their biology, biochemistry and production. England: Longman Group, 1993. p.5-22.

$\mathrm{KINI}$, F. et al. Chemical composition of the essential oil of Hyptis spicigera Lam. from Burkina Faso. Journal of Essential Oil Research, v.5, n.2, p.219-21, 1993.

MARTINS, E.R. et al. Essential oil in the taxonomy of Ocimum selloi Benth. Journal of the Brazilian Chemical Society, v.8, n.1, p.29-32, 1997.

MURASHIGE, T.; SKOOG, F. A revised medium for rapid growth and bioassays with tobacco tissue cultures. Physiologia Plantarum, v.15, n.3, p.473-97, 1962.

NATIONAL INSTITUTE OF STANDARDS AND TECHNOLOGY. PC version of the NIST/EPA/NIH Mass Spectral Database. Gaithersburg: Department of Commerce, 1998.

SALES, J.F. et al. Composition and chemical variability in the essential oil of Hyptis marrubioides Epl. Journal of Essential Oil Research, v.19, p.552-6, 2007.

SILVA, A.F.; BARBOSA, L.C.A.; SILVA, E.A.M. Composição química do óleo essencial de Hyptis suaveolens (L.) Poit. (Lamiaceae). Revista Brasileira de Plantas Medicinais, v.6, n.1, p.1-7, 2003.

SOUZA, L.K.H. et al. Antimicrobial activity of Hyptis ovalifolia towards dermatophytes. Memórias do Instituto Oswaldo Cruz, v.98, n.7, p.963-5, 2003.

Van Den DOOL, H.; KRATZ, P.D.J.A. Generalization of the retention index system including linear temperature programmed gas-liquid partition chromatography. Journal of Chromatography, v.11, n.4, p.463-71, 1963. WASICKY, R. Uma modificação do aparelho de Clevenger para extração de óleos essenciais. Revista Faculdade de Farmácia e Bioquímica, v.1, n.1, p.77-81, 1963. 